\section{The Wessex Recent In-Patient Suicide Study, 2}

\author{
Case-control study of 59 in-patient suicides ${ }^{\dagger}$
}

ELIZABETH A. KING, DAVID S. BALDWIN, JULIA M. A. SINCLAIR and MICHAEL J. CAMPBELL

\section{Background Psychiatric patients have} an elevated risk of suicide while in hospital.

\begin{abstract}
Aims To compare social, clinical and health-care delivery factors in in-patient and out-patient suicides and their controls.
\end{abstract}

Method Retrospective case-control study of 59 in-patients and 106 controls, matched for age, gender, diagnosis and admission date. Odds ratios were calculated using conditional multiple logistic regression.

Results There were seven independent increased-risk factors: history of deliberate self-harm, admission under the Mental Health Act, involvement of the police in admission, depressive symptoms, violence towards property, going absent without leave and a significant care professional being on leave. When compared with out-patient suicides, in-patients were more often female and male in-patients had a psychotic illness. Unlike the out-patient suicides, social factors were not found to be significant.

Conclusions The characteristics of inpatient and out-patient suicides differ. Identified risk factors have relatively low sensitivity and specificity.

Declaration of interest This study was funded by the NHS South \& West Research and Development Directorate.

†See part I, pp. 53I-536, this issue.
Approximately $25-40 \%$ of suicide victims are in contact with psychiatric services in the year before death (Pirkis \& Burgess, 1998; Appleby et al, 1999b); 14\% receive in-patient care during this time and onefifth of these $(3-4 \%$ of all suicides) die while in hospital (Proulx et al, 1997; Appleby et al, 1999a,b). Relatively few factors specific to in-patient suicide have been identified and they have limited predictive value (Powell et al, 2000). The Wessex Recent In-Patient Suicide Study is a case-control study to test two hypotheses: increased suicide risk is associated with particular patient characteristics; and decreased suicide risk is associated with continuity of care. The differences between 234 psychiatric patients who died within a year of discharge and 431 matched controls are reported elsewhere (King et al, 2001). We now compare 59 additional cases who died as in-patients with their matched controls, and also with those patients who committed suicide following discharge.

\section{METHOD}

The method is described fully elsewhere (King et al, 2001).

\section{Identification of cases}

The 373 patients who died by suicide within a year of their final hospital admission formed the overall patient group; 75 of these died while in hospital. The cases in this study were the 59 in-patients $(79 \%)$ for whom case notes could be found. Inpatient suicides who died in hospitals outside Wessex were excluded owing to the difficulties in obtaining ethical approval to inspect the notes of these individual patients.

\section{Matching with control patients}

Each index patient was matched with two controls using the following sequential criteria: gender, age, diagnostic group, ward type and admission date. Every index patient was matched with at least one control.

\section{Data collection}

One of us (J.M.A.S.) extracted demographic, clinical and health-care data from medical case notes onto the specifically designed study pro forma, with additional data (e.g. legal status and observation level) noted for index patients. When not recorded in the case notes, some further information relating to the circumstances of death (e.g. time of day, place and method of death) was derived from coroners' records, obtained as part of an ongoing audit of suicides in Wessex.

\section{Statistical procedures}

We performed univariate and multiple regression analyses using conditional logistic regression (Collett, 1991) in STATA 6 (StataCorp, 1999). We identified 60 potential variables for the in-patient deaths and 105 variables for the out-patient deaths, as already described. Stepwise backward elimination of variables, with probability for rejection set at 0.1 , was used to produce a parsimonious model. Nonconditional logistic regression was used in separate comparisons of in-patient and out-patient suicides and their controls.

\section{RESULTS}

\section{Study sample}

Of the 75 patients who died before discharge, 51 suicides $(68 \%)$ and 24 open verdicts $(32 \%)$ were returned. Six cases were excluded and in another ten the case notes were unavailable. The notes of five of these cases were located but they were stored in a room contaminated with blue asbestos and therefore were inaccessible. Of the remaining 59 cases, $47(80 \%)$ had two controls and 12 had one identifiable control. There were no differences in age and gender distribution between the 75 in-patient suicides and the 59 cases included in the study, but it was not possible to compare diagnoses.

The only pre-admission factor that differentiated index patients from controls was a history of deliberate self-harm (Table 1). There was no significant difference between the cases and controls in length of illness, number of previous 
Table I Clinical characteristics of cases and matched controls

\begin{tabular}{|c|c|c|c|c|c|c|}
\hline & \multicolumn{2}{|c|}{ Control group } & \multicolumn{2}{|c|}{ Index group } & \multirow[t]{2}{*}{$P$} & \multirow[t]{2}{*}{ Test } \\
\hline & $n=106$ & $\%$ & $n=59$ & $\%$ & & \\
\hline Length of psychiatric illness & \multicolumn{2}{|c|}{9.9 years } & \multicolumn{2}{|c|}{10.3 years } & 0.248 & $t$-test \\
\hline \multicolumn{7}{|l|}{ Number of admissions prior to index admission } \\
\hline None & 36 & 34 & 14 & 24 & & \\
\hline One & 12 & II & 13 & 22 & 0.124 & $\chi^{2}(2$ d.f.) \\
\hline Two or more & 58 & 55 & 32 & 54 & & \\
\hline Readmitted to different hospital & 13 & 12 & 12 & 20 & 0.180 & $\mathrm{FE}$ \\
\hline Readmitted under different consultant & 27 & 25 & 16 & 27 & 0.166 & $\chi^{2}$ \\
\hline Readmitted with different diagnosis & 8 & 8 & 3 & 5 & 0.399 & $\mathrm{FE}$ \\
\hline Concomitant physical illness & 32 & 30 & 17 & 29 & 0.853 & $\chi^{2}$ \\
\hline Family history of completed suicide & 7 & 7 & 7 & 12 & 0.269 & $\chi^{2}$ \\
\hline Family history of mental illness & 41 & 40 & 27 & 46 & 0.491 & $\chi^{2}$ \\
\hline History of deliberate self-harm & 52 & 49 & 43 & 73 & 0.003 & $\chi^{2}$ \\
\hline Additional Axis II disorder & 15 & 14 & 8 & 14 & 0.916 & $\chi^{2}$ \\
\hline History of problem drinking & 28 & 26 & 14 & 24 & 0.704 & $\chi^{2}$ \\
\hline History of illicit/prescribed substance misuse & 18 & 17 & 7 & 12 & 0.380 & $\chi^{2}$ \\
\hline
\end{tabular}

$\mathrm{FE}$, Fisher's exact test.

admissions or family history of either mental illness or suicide.

\section{Admission variables}

Of the 59 cases, 37 (63\%) had been admitted to old 'mental hospitals', 21 to district general hospital psychiatric units and 1 to a private hospital. Sixteen (27\%) in-patient deaths occurred within the first week of admission, $32(54 \%)$ between 1 week and 3 months, 7 (12\%) after 3 months and $4(7 \%)$ after more than 1 year.

\section{Gender differences between index patients}

The male/female in-patient suicide ratio was $1.2: 1$. Significantly more males $(13$, $40.6 \%)$ than females $(2,7.4 \%)$ suffered from schizophrenia or a schizophrenia-like illness (Table 2). A lifetime history of deliberate self-harm was present in 25 females $(92.6 \%)$ and 17 males $(53.1 \%)$.

\section{Circumstances of death}

Legal status of in-patient suicides

At the time of the event leading to death, 12 patients $(22.3 \%)$ were detained under the Mental Health Act 1983, 46 (78\%) were informal and 1 patient was on Section 17 leave from hospital.

\section{Observation status}

Fifteen $(25.4 \%)$ patients were on leave from hospital at the time of their death. Of those not on leave, $20(45 \%)$ were subject to regular checks and $18(41 \%)$ were subject to low-level routine or general observations. There was no record of observation status for six patients (14\%). Discharge plans were being made for $22 \%$ of the in-patient deaths. Only $44 \%$ of the patients were granted leave during the index admission, compared with $60 \%$ of controls. Of those who were granted leave, $35 \%$ of patients but only $5 \%$ of controls were recalled or returned earlier than planned.

\section{Noted suicide risk at last contact}

There was no significant difference between patients and controls in the suicide risk noted at admission. No record of suicide risk was made at last contact with a staff member in 28 cases $(47.5 \%)$. Risk factors for suicide were noted in 23 cases (39\%). For eight patients in whom the risk was both noted and quantified, the risk of suicide was considered low in five and high in three patients.

\section{Time of death}

The time of death for four patients was uncertain. Of those who died on hospital premises, 19 deaths $(73 \%)$ occurred on a weekday and 7 at the weekend. About half of these 26 deaths occurred during the day (42\% during weekdays and $57 \%$ at the weekend) and one-third during the evening or at night. There was no significant difference between the number of deaths in weekday $(49 \%)$ and weekend periods (44\%).

\section{Location}

Twenty-three patients $(39.0 \%)$ died on the ward or elsewhere in the hospital building and four $(6.8 \%)$ died within hospital grounds. Thirty-two patients $(54 \%)$ had

Table 2 Diagnoses of 59 in-patient suicides and 234 discharged patient suicides

\begin{tabular}{|c|c|c|c|c|c|c|c|c|c|c|c|c|}
\hline & \multicolumn{6}{|c|}{ In-patient suicides $(n=59)$} & \multicolumn{6}{|c|}{ Discharged patient suicides $(n=234)$} \\
\hline & \multicolumn{2}{|c|}{ Male } & \multicolumn{2}{|c|}{ Female } & \multicolumn{2}{|c|}{ Total } & \multicolumn{2}{|c|}{ Male } & \multicolumn{2}{|c|}{ Female } & \multicolumn{2}{|c|}{ Total } \\
\hline & $n=32$ & $\%$ & $n=27$ & $\%$ & $n=59$ & $\%$ & $n=145$ & $\%$ & $n=89$ & $\%$ & $n=234$ & $\%$ \\
\hline Male/female ratio & \multicolumn{2}{|c|}{1.2} & \multicolumn{2}{|c|}{ I } & & & \multicolumn{2}{|c|}{1.6} & \multicolumn{2}{|c|}{ I } & & \\
\hline Schizophrenia and schizophrenia-like disorders & 13 & 40.6 & 2 & 7.4 & 15 & 25.4 & 31 & 21.4 & 10 & 11.2 & 41 & 17.5 \\
\hline Psychotic affective disorders & 6 & 22.2 & 6 & 22.2 & 12 & 20.3 & 26 & 17.9 & 24 & 27.0 & 50 & 21.4 \\
\hline Non-psychotic affective disorders & 12 & 37.5 & 15 & 55.6 & 27 & 45.8 & 60 & 41.4 & 44 & 49.4 & 104 & 44.4 \\
\hline Residual diagnoses & I & 3.1 & 3 & II.I & 4 & 6.8 & 28 & 19 & 10 & 11.2 & 38 & 16.2 \\
\hline Other & & & I & 3.7 & I & 1.7 & & & I & I.I & I & 0.43 \\
\hline
\end{tabular}


Table 3 Factors from univariate analysis $(P<0.20)$ and multiple logistic regression

\begin{tabular}{|c|c|c|c|c|c|c|c|c|}
\hline \multirow[t]{2}{*}{ Factor } & \multirow{2}{*}{$\begin{array}{l}\text { Controls } \\
n=106(\%)\end{array}$} & \multirow{2}{*}{$\begin{array}{c}\text { Cases } \\
n=59(\%)\end{array}$} & \multicolumn{3}{|c|}{ Univariate } & \multicolumn{3}{|c|}{ Multivariate } \\
\hline & & & Odds ratio & $95 \% \mathrm{Cl}$ & $P$ & Odds ratio & $95 \% \mathrm{Cl}$ & $P$ \\
\hline \multicolumn{9}{|l|}{ Psychiatric history } \\
\hline History of DSH before admission & $52(49)$ & $42(7 \mathrm{I})$ & 2.23 & I.I5-4.34 & 0.017 & 3.37 & $0.93-12.16$ & 0.063 \\
\hline \multicolumn{9}{|l|}{ Reason for admission } \\
\hline Aggression with others & $12(I I)$ & II (I9) & 1.97 & $0.73-5.32$ & 0.193 & 0.73 & $0.04-14.0 \mid$ & 0.835 \\
\hline Suicidal ideation & $37(35)$ & $31(52)$ & 2.35 & $1.14-4.85$ & 0.021 & 2.64 & $0.45-15.43$ & 0.281 \\
\hline Loss of social support/social factors & $50(47)$ & $20(34)$ & 0.61 & $0.31-1.18$ & 0.142 & 1.13 & $0.336-3.553$ & 0.830 \\
\hline Planned admission & $13(12)$ & $3(5)$ & 0.36 & $0.10-1.30$ & 0.120 & 0.63 & $0.66-5.97$ & 0.685 \\
\hline Admitted under MHA & 7 (7) & $12(20)$ & 3.27 & $1.21-8.84$ & 0.019 & 328.30 & $8.34-12920$ & 0.002 \\
\hline \multicolumn{9}{|c|}{ Symptoms elicited and noted at Mental State Examination } \\
\hline Hopelessness & $16(15.1)$ & $16(27)$ & 2.26 & $0.95-5.306$ & 0.064 & 0.41 & $0.08-2.06$ & 0.278 \\
\hline Suicidal ideas & $34(32)$ & $28(47)$ & 2.36 & $1.08-5.182$ & 0.032 & 0.42 & $0.06-3.02$ & 0.388 \\
\hline Hostility & $10(9)$ & $10(17)$ & 2.25 & $0.78-6.47$ & 0.134 & 1.85 & $0.04-77.06$ & 0.746 \\
\hline \multicolumn{9}{|l|}{ Events during admission } \\
\hline MHA applied & $20(19)$ & $22(37)$ & 2.97 & $1.32-6.65$ & 0.008 & 0.02 & $0.00-1.04$ & 0.052 \\
\hline Violence to property by patient & 4 (4) & $9(15)$ & 4.99 & $1.33-18.7 \mid$ & 0.017 & 6.26 & $0.51-76.78$ & 0.151 \\
\hline DSH during admission & 7 (7) & $12(20)$ & 3.95 & $1.37-11.39$ & 0.011 & 1.26 & $0.23-7.03$ & 0.790 \\
\hline Threat of self-discharge requiring detention & $14(13)$ & $18(31)$ & 3.40 & $1.38-8.4 \mid$ & 0.008 & 62.11 & $1.03-3722.38$ & 0.048 \\
\hline Patient went AWOL & $13(12)$ & $21(36)$ & 5.55 & $2.03-15.12$ & 0.001 & 22.96 & $2.31-228.31$ & 0.008 \\
\hline Change of consultant during admission & $6(6)$ & II (I9) & 3.97 & I.37-II.54 & 0.011 & 14.79 & $0.99-220.46$ & 0.051 \\
\hline Key professional leaving/on leave & $3(3)$ & $7(12)$ & 4.13 & $1.06-16.11$ & 0.041 & 16.42 & $1.90-|4| .76$ & 0.011 \\
\hline
\end{tabular}

DSH, deliberate self-harm; MHA, Mental Health Act 1983; AWOL, absent without leave.

left the hospital grounds before the event leading to their death (17 were either on leave or out with permission but 15 had not been granted leave): 12 patients died at home, 1 died on a boat and 19 died elsewhere.

\section{Cause of death}

Information from inquest files indicated that hanging was the most common cause of death among in-patients of either gender, accounting for $41 \%$ of male and $44 \%$ of female deaths. Twelve of the 16 men and 7 of the 10 women hanged themselves in the ward area. Thirty per cent of females but only six per cent of males died from a drug overdose. Currently prescribed drugs were not used by any of the five patients who took fatal overdoses while in the ward. Half of the drug overdoses were taken away from the ward. Of the 19 patients $(32 \%)$ who died away from hospital premises, 8 men and 2 women were killed by trains or other moving vehicles.

\section{Contact with others after death}

Relatives were telephoned after the death of 36 patients $(61.1 \%)$; in 24 instances the telephone call was followed by face-to-face contact. The relatives of 4 suicides $(6.8 \%)$ were contacted face-to-face. In 19 patients $(32.2 \%)$ there was no record of contact with relatives; for 4 of these, contact was made with the patient's general practitioner.

\section{Differences between in-patient and out-patient suicides}

Relatively more of the in-patient suicides were women (male/female ratio 1.2:1). The diagnostic distribution is shown in Table 2. In both in-patient and out-patient suicides the majority of patients with schizophrenia and schizophrenia-like disorders were male. Psychotic and nonpsychotic affective disorders were present in a similar proportion of in-patient and out-patient suicides.

\section{Comparison between in-patient suicides and matched controls}

Table 3 summarises the 18 variables with a $P$ value of $<0.20$ in the univariate model and the results of the multiple regression used to produce a parsimonious model. The seven independent variables associated with an increased risk of suicide that remained in the model after backward elimination of variables (with probability for rejection set at 0.1 ) are shown in Table 4.

\section{Number of risk factors}

Significantly more patients $(30,51 \%)$ than controls $(12,11.3 \%)$ had three or more of the seven risk factors (Table 5). No social factors were found to discriminate between patients and controls. Admission under the Mental Health Act and depressive symptoms elicited on admission were independently associated with increased risk of suicide. 
Table 4 Variables remaining after backward elimination from multiple logistic regression model with probability for rejection set at $P<0$. I

\begin{tabular}{|c|c|c|c|c|c|c|c|}
\hline \multirow[t]{2}{*}{ Variable } & \multicolumn{2}{|c|}{ Controls (valid $n=106$ ) } & \multicolumn{2}{|c|}{ Index (valid $n=59)$} & \multirow[t]{2}{*}{ Odds ratio } & \multirow[t]{2}{*}{$95 \% \mathrm{Cl}$} & \multirow[t]{2}{*}{$P$} \\
\hline & $n$ & $\%$ & $n$ & $\%$ & & & \\
\hline History of DSH before index admission & 52 & 49 & 42 & 72 & 2.59 & $0.86-7.80$ & 0.090 \\
\hline Admission under MHA & 7 & 7 & 12 & 20 & 49.83 & $4.97-500.01$ & 0.001 \\
\hline Admitted after involvement with police & II & 10 & 13 & 22 & 4.59 & $0.88-24.07$ & 0.071 \\
\hline Depressive symptoms elicited at admission & 65 & 61 & 45 & 76 & 23.45 & $3.93-140.13$ & 0.001 \\
\hline \multicolumn{8}{|l|}{ Events during admission } \\
\hline Significant professional leaving/on leave & 3 & 3 & 7 & 12 & $|7.5|$ & $2.68-114.50$ & 0.003 \\
\hline Went AWOL & 13 & 12 & 21 & 36 & 13.05 & $2.25-75.78$ & 0.004 \\
\hline Showed violence to property & 4 & 4 & 9 & 15 & 10.13 & $1.54-66.63$ & 0.016 \\
\hline
\end{tabular}

DSH, deliberate self-harm; MHA, Mental Health Act 1983; AWOL, absent without leave.

Table 5 Number of suicide risk factors among index and control in-patients

\begin{tabular}{|c|c|c|c|c|}
\hline \multirow{2}{*}{$\begin{array}{l}\text { Number of risk factors } \\
(\text { maximum }=7)\end{array}$} & \multicolumn{2}{|c|}{ Control $(n=106)$} & \multicolumn{2}{|c|}{ Index $(n=59)$} \\
\hline & $n$ & $\%$ & $n$ & $\%$ \\
\hline 0 & 12 & II.3 & 0 & \\
\hline I & 46 & 43.4 & 7 & 11.9 \\
\hline 2 & 36 & 34.0 & 22 & 37.3 \\
\hline 3 & II & 10.4 & 24 & 40.7 \\
\hline 4 & I & 0.9 & 4 & 6.8 \\
\hline 5 & 0 & & 2 & 3.4 \\
\hline Total & 106 & 100 & 59 & 100 \\
\hline
\end{tabular}

\section{Events during admission}

A display of violence to property and going absent without leave (AWOL) were both associated with suicide, as was a significant professional leaving employment or going on leave.

\section{Comparison between in-patient and out-patient suicides and controls}

\section{Index patients}

Admission under the Mental Health Act, going absent without leave or showing violence to property during the final

Table 6 Differences between 59 in-patient suicides and 234 discharged patient suicides and between 106 in-patient suicide controls and 43 I discharged in-patient controls (univariate logistic regression)

\begin{tabular}{|c|c|c|c|c|c|c|c|}
\hline \multirow[t]{2}{*}{ In-patient $v$. out-patient } & \multicolumn{2}{|c|}{ In-patient suicides $(n=59)$} & \multicolumn{2}{|c|}{ Out-patient suicides $(n=234)$} & \multirow[t]{2}{*}{ Odds ratio } & \multirow[t]{2}{*}{$95 \% \mathrm{Cl}$} & \multirow[t]{2}{*}{$P$} \\
\hline & $n$ & $\%$ & $n$ & $\%$ & & & \\
\hline \multicolumn{8}{|l|}{ Index } \\
\hline History of DSH before admission & 42 & 71.2 & 157 & 67.1 & I.2I & $0.65-2.27$ & 0.548 \\
\hline Admission under MHA & 12 & 20.3 & 20 & 8.6 & 2.73 & $1.25-5.97$ & 0.012 \\
\hline Depressive symptoms at mental state examination & 45 & 76.3 & 167 & 71.4 & $\mathrm{I} .4 \mathrm{I}$ & $0.72-2.79$ & 0.311 \\
\hline Key professional leaving/on leave & 7 & 11.9 & 12 & 5.1 & 2.49 & $0.93-6.63$ & 0.068 \\
\hline Went AWOL & 21 & 35.6 & 29 & 12.4 & 3.91 & $2.02-7.56$ & $<0.001$ \\
\hline Showed violence to property & 9 & 15.3 & 12 & 5.1 & 3.33 & $1.33-8.33$ & 0.010 \\
\hline Control & \multicolumn{2}{|c|}{ In-patient controls $(n=106)$} & \multicolumn{2}{|c|}{ Out-patient controls $(n=43 \mathrm{I})$} & & & \\
\hline History of DSH before admission & 52 & 49.1 & 179 & 41.5 & 1.36 & $0.89-2.08$ & 0.162 \\
\hline Admitted after involvement with police & II & 10.4 & 45 & 10.4 & 0.99 & $0.49-1.99$ & 0.985 \\
\hline Admissions under MHA & 7 & 6.6 & 35 & 8.1 & 0.80 & $0.35-1.85$ & 0.603 \\
\hline Depressive symptoms at mental state examination & 65 & 61.3 & 275 & 63.8 & 0.90 & $0.58-1.39$ & 0.635 \\
\hline Key professional leaving/on leave & 3 & 2.8 & 4 & 0.9 & 3.11 & $0.68-4.10$ & 0.142 \\
\hline Went AWOL & 13 & 12.3 & 37 & 8.6 & 1.49 & $0.76-2.91$ & 0.245 \\
\hline Showed violence to property & 4 & 3.8 & 19 & 4.4 & 0.85 & $0.28-0.55$ & 0.773 \\
\hline
\end{tabular}

DSH, deliberate self-harm; MHA, Mental Health Act 1983; AWOL, absent without leave. 
Table 7 Comparison of independent factors associated with increased suicide risk in in-patient suicides and out-patient suicides: factors from multivariate logistic regression analysis remaining after backward elimination of variables with a $P$ value for rejection of 0.10

\begin{tabular}{|c|c|c|c|c|c|c|c|c|c|c|}
\hline \multirow[t]{2}{*}{ Factor } & \multicolumn{5}{|c|}{ In-patients } & \multicolumn{5}{|c|}{ Out-patients } \\
\hline & $\begin{array}{c}\text { Control } \\
n=106(\%)\end{array}$ & $\begin{array}{c}\text { Index } \\
n=59(\%)\end{array}$ & Odds ratio & $95 \% \mathrm{Cl}$ & $P$ & $\begin{array}{c}\text { Control } \\
n=431 \text { (\%) }\end{array}$ & $\begin{array}{c}\text { Index } \\
n=234 \text { (\%) }\end{array}$ & Odds ratio & $95 \% \mathrm{Cl}$ & $P$ \\
\hline \multicolumn{11}{|l|}{ Social/demographic } \\
\hline Living alone & & & & & & $135(31)$ & $95(4 I)$ & 1.87 & $1.19-2.93$ & 0.006 \\
\hline Not White & & & & & & $23(5)$ & $24(10)$ & 2.22 & $1.04-4.75$ & 0.039 \\
\hline \multicolumn{11}{|l|}{ Index admission } \\
\hline New' consultant & & & & & & $23 \mathrm{I}(54)$ & $147(63)$ & 1.56 & $\mathrm{I} .0 \mathrm{I}-2.4 \mathrm{I}$ & 0.042 \\
\hline Admitted under MHA & 7 (7) & $12(20)$ & 49.83 & $5.0-500$ & 0.001 & & & & & \\
\hline \multicolumn{11}{|l|}{ Psychiatric history } \\
\hline History of DSH & $52(49)$ & $42(71)$ & 2.59 & $0.86-7.8$ & 0.09 & $179(44.3)$ & I57 (69.8) & 3.61 & $2.34-5.59$ & $<0.001$ \\
\hline \multicolumn{11}{|l|}{ Reason for admission } \\
\hline Involved with police & II (10) & $13(22)$ & 4.59 & $0.9-24.1$ & 0.071 & & & & & \\
\hline \multicolumn{11}{|c|}{ Symptoms elicited and recorded at admission } \\
\hline Suicidal ideation & & & & & & $160(39.6)$ & II4 (50.7) & 2.0 & $1.3-3.1$ & 0.002 \\
\hline Hopelessness & & & & & & $58(14.4)$ & $62(27.6)$ & 1.8 & $1.07-14.2$ & 0.026 \\
\hline Depressive features & $65(61)$ & $46(78)$ & 23.45 & $3.9-140$ & 0.001 & & & & & \\
\hline \multicolumn{11}{|l|}{ Events after admission } \\
\hline Went AWOL & $13(12)$ & $21(36)$ & 13.05 & $2.2-75.8$ & 0.004 & & & & & \\
\hline Showed violence to property & $4(4)$ & $9(15)$ & 10.13 & $1.5-66.7$ & 0.016 & & & & & \\
\hline Key professional leaving/on leave & $3(3)$ & $7(12)$ & 17.51 & $2.7-114$ & 0.003 & & & & & \\
\hline Loss of job & & & & & & $5(1.2)$ & $12(6.3)$ & 7.2 & $2.0-26.2$ & 0.003 \\
\hline New relationship problem & & & & & & $7(1.7)$ & II (4.9) & 4.1 & $1.2-14.2$ & 0.029 \\
\hline \multicolumn{11}{|l|}{ Events post-discharge } \\
\hline Key professional leaving/on leave & & & & & & $4(1.0)$ & $12(5.3)$ & 13.9 & $3.0-63.9$ & 0.001 \\
\hline
\end{tabular}

MHA, Mental Health Act 1983; DSH, deliberate self-harm; AWOL, absent without leave.

I. 'New' consultant is either consultant at first admission or, if not first admission, readmitted under care of different consultant.

admission occurred significantly more frequently in in-patient than out-patient cases (Table 6).

There was no significant difference between in-patient and out-patient suicides in the presence of depressive symptoms at admission $(76.3 \% v .71 .4 \%)$ or the absence of a significant health-care professional at the time of the event leading to death $(2.8 \% v .0 .9 \%)$. The social factors associated with an altered risk of suicide following discharge do not appear to affect the risk of in-patient suicide (King et al, 2001) (Table 7).

\section{Controls}

In-patient controls and out-patient controls did not differ in any of these variables.

\section{DISCUSSION}

We have identified seven factors associated with a significant increase in the risk of suicide while receiving psychiatric inpatient care.

\section{Study limitations}

As described in the accompanying paper (King et al, 2001), this study has three limitations. The first is the reliance on data collected retrospectively from case notes not intended for research purposes. The second is that the data collection was not performed blind to patient outcome. The final limitation is that many variables were analysed, although these were identified as potential factors a priori, with correction for multiple variables.

\section{Study strengths}

However, the study design has several advantages. First, data were collected using a standardised instrument, with operationally defined criteria. The patients were identified through the long-running Wessex Suicide Audit with ready access to coroners' records. Because of its size, data could be limited to a period of 8 years, in contrast to a recent study in which data were derived from admissions over a 30-year period (Powell et al, 2000).

\section{Comparison with previous investigations}

The in-patient suicides in this study are similar to those in previous cohorts, irrespective of country, including New Zealand (Read et al, 1993), Australia (Shah \& Ganesvaran, 1997), Canada (Proulx et al, 1997) and Ireland (Coakley et al, 1996). There are similarities in the proportion of patients with psychotic illnesses, particularly schizophrenia (Modestin \& Hoffmann, 1989; Coakley et al, 1996; Proulx et al, 1997; Shah \& Ganesvaran, 1997), and in those with a history of deliberate self-harm or requiring compulsory admission (Read et al, 1993). Furthermore, there are similarities in deaths from hanging or associated with moving vehicles, and in the prevalence of deaths occurring away from the ward (Proulx et al, 1997; Shah \& Ganesvaran, 1997). As such, the findings of this study may be widely applicable. 


\section{Comparison with out-patient suicides}

There is a relative excess of female in patient suicides, the male/female ratio being 1.2:1, similar to that found in other studies (Proulx et al, 1997; Powell et al, 2000). Certain risk factors for suicide in inpatients, such as admission under the Mental Health Act, involvement of police, violence towards property and going absent without leave, may reflect greater turmoil than is seen in those patients who kill themselves after discharge. Social factors appear relatively more important in out-patient suicides.

\section{Implications for clinical practice}

Six of the seven identified risk factors for in-patient suicide are patient-related. Four of these are factors generally recorded on admission (being admitted under the Mental Health Act, or after involvement with police, the presence of depressive symptoms and a history of deliberate self-harm). The other two, namely display of violence to property and going absent without leave, were recorded during admission.

The six patient-related factors are easily recorded, either as part of the standard admission procedure or in routine ward observations. Some factors are common, such as the presence of depressive symptoms, but others occur less often, for example being admitted under the Mental Health Act and/or via the police. Violence to property and being AWOL are relatively infrequent. When health professionals are about to go on leave it may be advisable to make careful arrangements for continuity of care, particularly if other risk factors are present.

Self-poisoning represents a much lower proportion of in-patient than out-patient suicides. Because none of the in-patients who died from a fatal overdose used currently prescribed medication, this suggests that restricting access to potentially fatal means can reduce the number of drugrelated deaths. Restricting the means of self-hanging is more difficult, but optimising the ward environment and patient observation has the potential to make some impact on in-patient deaths.

There was no difference in recorded suicide risk in either patients or controls at admission, but in almost half of the cases no statement of risk had been recorded by staff at their last contact with the patient. Continuing the risk assessment process throughout hospital care may allow potential risk and protective factors to be identified.

\section{CLINICAL IMPLICATIONS}

Seven independent risk factors distinguish cases from controls.

In-patient and out-patient suicides differ in certain characteristics, the in-patients showing greater signs of personal turmoil.

Restricting access to potentially fatal methods may prevent some deaths.

\section{LIMITATIONS}

Data were collected retrospectively, and not blind to patient outcome.

The number of in-patient deaths was not great $(n=59)$ and occurred over 8 years.

The findings require confirmation in a prospective study.

ELIZABETH A. KING, PhD, DAVID S. BALDWIN, MRCPsych, JULIA M. A. SINCLAIR, MRCPsych, Mental Health Group, Department of Psychiatry, The University of Southampton, Southampton; MICHAEL J. CAMPBELL, PhD, Institute of General Practice and Primary Care, School of Health and Related Research, The University of Sheffield, Sheffield, UK

Correspondence: Dr Elizabeth A. King, Mental Health Group, University Department of Psychiatry, RSH Hospital, Brinton's Terrace, Southampton SOI4 0YG,UK. E-mail: eak@soton.ac.uk

(First received 2 May 2000, final revision II December 2000, accepted I5 December 2000)

Although the odds ratios for risk factors are high, they occur in only a minority of patients and thus the sensitivity of individual risk factors is low.

The risk of suicide is present in many psychiatric in-patients. Although the ability to predict suicide accurately is limited, the conscientious and continuing assessment of individual risk and thoughtful policies and procedures may prevent some fatal outcomes (Sederer, 1994).

\section{ACKNOWLEDGEMENTS}

This work was undertaken through a grant from the South and West Health Authority Research and Development Directorate, with an additional grant from the Research Support Subcommittee of the University of Southampton.

\section{REFERENCES}

Appleby, L., Dennehy, J. A., Thomas, C. S., et al (1999a) Aftercare and clinical characteristics of people with mental illness who commit suicide: a case-control study. Lancet, 353, 1397-1400.

_ , Shaw, J., Amos, T., et al (1999b) Suicide within 12 months of contact with mental health services: national clinical survey. British Medical Journal, 318, 1235-1239.

Coakley, G. M., Carey, T. G. \& Owens, J. M. (1996) A study of psychiatric inpatient suicides. Irish Journal of Psychological Medicine, 13, 102-104.
Collett, D. (199I) Modelling Binary Data. London: Chapman \& Hall.

King, E. A., Baldwin, D. S., Sinclair, J. M. A., et a (200I) The Wessex Recent In-Patient Suicide Study, I. Case-control study of 234 recently discharged psychiatric patient suicides. British Journal of Psychiatry I78, 531-536.

Modestin, J. \& Hoffmann, H. (1989) Complete suicide in psychiatric inpatients and former inpatients. A comparative study. Acta Psychiatrica Scandinavica, 79, 229-234.

Pirkis, J. \& Burgess, P. (1998) Suicides and recency of health care contacts. A systematic review. British Journal of Psychiatry, 173, 462-474.

Powell, J., Geddes, J., Deeks, J., et al (2000) Suicide in psychiatric hospital in-patients. Risk factors and their predictive power. British Journal of Psychiatry, 176, 266-272.

Proulx, F., Lesage, A. D. \& Grunberg, F. (1997) One hundred in-patient suicides. British Journal of Psychiatry, I7I, 247-250.

Read, D. A., Thomas, C. S. \& Mellsop, G. W. (1993) Suicide among psychiatric in-patients in the Wellington region. Australian and New Zealand Journal of Psychiatry, 27. 392-398.

Sederer, L. I. (1994) Managing suicidal inpatients. Death Studies, 18, 47I-482.

Shah, A. K. \& Ganesvaran, T. (1997) Inpatient suicides in an Australian mental hospital. Australian and New Zealand Journal of Psychiatry, 31, 291-298.

StataCorp (1999) Statistical Software: Release 6.0. College Station, TX: Stata Corporation. 